\title{
Need for public awareness regarding low birth weight and bottle feeding
}

\author{
Hypertension Research (2016) 39, 825-826; doi:10.1038/hr.2016.77; published online 23 June 2016
}

Recently, Ruggajo et al. ${ }^{1}$ reported the Norwegian registration study regarding low birth weight (LBW) and end-stage renal disease (ESRD). They concluded that LBW, rather than familial factors, is a significant risk for future ESRD. We read the article $^{1}$ with great interest because as they cited, $\mathrm{we}^{2}$ also reported a nationwide study showing strong associations between LBW and ESRD, and reaffirmed the significance of the article by Hosaka et al., ${ }^{3}$ which was published in the journal, Hypertension Research.

According to a report from United Nations Children's Fund, ${ }^{4}$ Norway had the sixth lowest LBW prevalence (5.4\%) among 27 developed countries, whereas Japan had the highest LBW prevalence (9.6\%). Although the LBW prevalence is higher in Japan, the annual incidences of ESRD in Norway and Japan are similar with 285 and 290 persons per million, respectively, diagnosed each year. However, the ESRD incidences among individuals of $<20$ years are higher in Japan $(0.3 \%)$ compared with in Norway $(0.03 \%)^{1,5}$ supporting Ruggajo's hypothesis that LBW strongly affects ESRD onset, especially in persons of $<20$ years, and they postulated that this association is not explained by familial factors. ${ }^{1}$ A good example from our experience serves to illustrate this point: a 20 -year-old woman with proteinuria and renal insufficiency exhibited hypertrophic glomeruli and severe arteriolosclerosis, which is suggestive of glomerular hypertension, in renal biopsy specimens (Figure 1). These findings are well explained by Barker's fetal origin of adult-age diseases theory and Brenner's hyperfiltration hypothesis. Thus, LBW was accompanied by a low nephron number, resulting in glomerular hypertension and further glomerular injury. ${ }^{6}$ These mechanisms were described as a vicious cycle resulting in further nephron loss. ${ }^{7}$ The patient was born as an identical twin, with a birth weight of $2015 \mathrm{~g}$, at 39 weeks gestation and was bottle fed during the newborn period. Her identical twin, who also had LBW but was breastfed, currently had no kidney dysfunction or proteinuria. Because bottle feeding in infancy is unfavorable for later life compared with breastfeeding, ${ }^{8,9}$ the patient's renal dysfunction may be attributable to bottle feeding. Breast milk is known to contain hormones, such as leptin, ghrelin and adiponectin, which have long-term 'epigenetic' effects on energy metabolism and on feeding behavior. ${ }^{10}$ In addition, using the data from the Tohoku Study of Child Development, Hosaka et al. ${ }^{3}$ demonstrated that breastfeeding can lower home blood pressure in children at 7 years of age, regardless of their mother's blood pressure. ${ }^{11}$ They cited higher sodium concentrations in formula milk compared with breast milk. ${ }^{3}$ This serves as a reminder of the thesis that breastfed babies can learn effective self-regulation of dietary intake and favorable taste preferences. ${ }^{12}$

Even in adult individuals, increases in dietary salt taste stimulate a preference for salty foods. Decreases in the amount of sodium contained in processed food (that is, non-discretionary salt) are needed to reduce national salt consumption $<6$ g per day. Therefore, we are encouraged by the news that as a first step in this process (political and social approach), the Salt Reduction Committee, Japanese Society of Hypertension, has lobbied relevant government ministries and has succeeded in changing food labeling standards to identify the 'sodium' value as the 'corresponding salt' value.

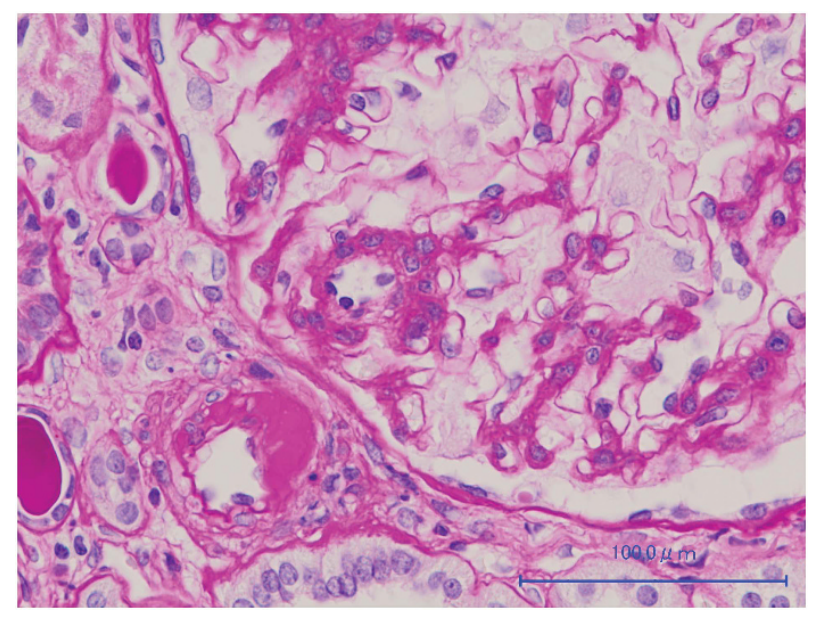

Figure 1 Renal biopsy findings in a 20-year-old woman. All glomeruli were enlarged, with diameters of $250 \mu \mathrm{m}$. Most arterioles showed prominent subendothelial hyaline deposition equivalent to ah3 grade, using the quantitative criteria for arteriolar hyaline thickening of the Banff 97 classification. Factors known to accompany arteriolosclerosis, such as hypertension or diabetes mellitus, were absent, and LBW (low birth weight) was the cause of the findings. PAS (periodic acid-Schiff) stain, original magnification $\times 400$. 
In conclusion, as mentioned above, the incidence of LBW has markedly increased in Japan, whereas other developed countries, such as the USA and Canada, have experienced the opposite trend during the same period. The increase in LBW in Japan appears to be attributable to very low mortality among newborn babies, as well as increased numbers of preterm deliveries and multiple gestations, and the drastic desire among Japanese women to be slender. Therefore, we must raise public awareness that maternal malnutrition during pregnancy and bottle feeding in infancy may result in infants having future risks of adult-onset diseases, such as hypertension, ischemic heart disease and chronic kidney disease.

\section{CONFLICT OF INTEREST}

The authors declare no conflict of interest.

Toshiyuki Miura, Michio Fukuda, Masashi Mizuno and Nobuyuki Ohte

Department of Cardio-Renal Medicine and Hypertension, Nagoya City University
Graduate School of Medical Sciences,
Nagoya, Japan
E-mail: m-fukuda@med.nagoya-cu.ac.jp

Ruggajo $P$, Skrunes R, Svarstad E, Skjærven R, Reisæther AV, Vikse BE. Familial factors, low birth weight, and development of esrd: a nationwide registry study. Am J Kidney Dis 2016; 67: 601-608

2 Ichikawa T, Fukuda M, Wakamatsu-Yamanaka T, Sato R, Naito T, Togawa $H$, Sasakawa $Y$, Tomonari $\mathrm{T}$, Mizuno $\mathrm{M}$, Miura $\mathrm{T}$, Kato $\mathrm{Y}$, Ono $\mathrm{M}$, Shirasawa Y, Ito A, Yoshida A, Kimura G. Low birth weight and end-stage renal disease: demographic analysis by region in Japan. Clin Exp Nephrol 2012; 16: 596-603.

3 Hosaka M, Asayama K, Staessen JA, Ohkubo T, Hayashi K, Tatsuta N, Kurokawa N, Satoh M, Hashimoto T, Hirose T, Obara T, Metoki H, Inoue R, Kikuya M, Nakai K, Imai Y, Satoh H. Breastfeeding leads to lower blood pressure in 7-year-old Japanese children: Tohoku Study of Child Development. Hypertens Res 2013; 36: 117-122.

4 UNICEF Office of Research. Child Well-being in Rich Countries: A Comparative Overview. Innocenti Report Card 11, pp. 13, 2013.

5 Japanese Society Dialysis Therapy. An overview of regular dialysis treatment in Japan. Available at http:// docs.jsdt.or.jp/overview/pdf2015/p009.pdf (accessed on 31 December 2014).
6 Brenner BM, Chertow GM. Congenital oligonephropathy and the etiology of adult hypertension and progressive renal injury. Am J Kidney Dis 1994; 23: 171-175.

7 Kanzaki G, Tsuboi N, Haruhara K, Koike K, Ogura M, Shimizu A, Yokoo T. Factors associated with a vicious cycle involving a low nephron number, hypertension and chronic kidney disease. Hypertens Res 2015; 38: 633-641.

8 Owen CG, Whincup PH, Gilg JA, Cook DG. Effect of breast feeding in infancy on blood pressure in later life: systematic review and meta-analysis. BMJ 2003; 327: 1189-1195.

9 Singhal A, Cole TJ, Lucas A. Early nutrition in preterm infants and later blood pressure: two cohorts after randomised trials. Lancet 2001; 357: 413-419.

10 Yamauchi T, Kamon J, Waki H, Terauchi Y, Kubota N, Hara K, Mori Y, Ide T, Murakami K, TsuboyamaKasaoka N, Ezaki O, Akanuma Y, Gavrilova O, Vinson C, Reitman ML, Kagechika $H$, Shudo K, Yoda M, Nakano Y, Tobe K, Nagai R, Kimura S, Tomita M, Froguel $\mathrm{P}$, Kadowaki $\mathrm{T}$. The fat-derived hormone adiponectin reverses insulin resistance associated with both lipoatrophy and obesity. Nat Med 2001; 7 : 941-946.

11 Hosaka M, Asayama K, Staessen JA, Tatsuta N, Satoh M, Kikuya M, Ohkubo T, Satoh H, Imai Y, Nakai K. Relationship between maternal gestational hypertension and home blood pressure in 7-year-old children and their mothers: Tohoku Study of Child Development. Hypertens Res 2015; 38: 776-782.

12 Li R, Fein SB, Grummer-Strawn LM. Do infants fed from bottles lack self-regulation of milk intake compared with directly breastfed infants? Pediatrics 2010; 125: e1386-e1393. 